\title{
Dust forecasting in the Hunter Valley, Australia
}

\author{
S. Lakmaker \\ Jacobs, Newcastle, Australia
}

\begin{abstract}
Coal mining is one of the main industries in the Hunter Valley region of New South Wales (NSW), Australia. From an environmental perspective, dust and the contribution from mining is a key topic of discussion by industry, regulators and the community. While measured dust levels are influenced by many sources, the local mining industry generally aims to manage site emissions as far as is reasonably practicable. To assist with the management of dust emissions from coal mines in the Hunter Valley, the Australian Coal Association Research Program funded a project (C19034) to develop an emission estimation and air dispersion modelling system. This paper describes the system and its key outcomes. The main objective of the system is to issue dust and meteorological forecasts so that operations can plan for and implement suitable emission reduction measures in advance of potentially adverse conditions. The system makes use of the CSIRO's computer-based air dispersion model known as TAPM (The Air Pollution Model). This model is provided with estimates of mine site dust emissions and forecasts of meteorological conditions to predict ambient dust concentrations in the Hunter Valley, for up to two days in advance. Dust concentrations are represented as an air quality index, consistent with the approach adopted by the NSW Office of Environment and Heritage. Forecasts are delivered via a daily email and detailed system outputs are uploaded to a dedicated web-site that can be accessed at any time by relevant stakeholders. Interest in the system has grown since its development and the main factor for the take up appears to be the simplistic nature of the outputs. Further work could involve improving the emission estimation, especially during rainfall events, to improve the overall performance of the system.
\end{abstract}

Keywords: mining, forecasting, dust, TAPM, environmental. 


\section{Introduction}

The Hunter Valley of NSW continues to experience unprecedented pressure in relation to concerns about the impacts of mining on regional air quality. This pressure has often led to delays in project approvals due to an increasing need for the industry to demonstrate that proactive measures are being undertaken to minimise air quality impacts. In addition, contemporary development consent conditions are requiring predictive meteorological and/or air dispersion modelling to assist with the planning of day-to-day activities. An example development consent condition is outlined in Table 1 below.

Table 1: Example consent condition relating to air quality forecasting [1].

"operate a comprehensive air quality management system that uses a combination of predictive meteorological forecasting, predictive air dispersion modelling and real-time air quality monitoring data to guide the day-to-day planning of mining operations and implementation of both proactive and reactive air quality mitigation measures to ensure compliance with the relevant conditions of this consent"

This paper provides an overview of the key air quality issues in the Hunter Valley, with a focus on local mining. It also provides some background to a regional dust forecasting system (which indirectly addresses contemporary development consent conditions) including outcomes to date.

\section{Air quality issues in the Hunter Valley}

The Hunter Valley extends approximately 150 kilometres $(\mathrm{km})$ northwest from Newcastle and accommodates in the order of 30 open-cut and underground coal mines (refer to Figure 1). Electricity generation, horse breeding, agriculture and cropping are also important industries for the region. The main population centres for the mid to upper Hunter are the towns of Singleton and Muswellbrook, each with populations of around 15,000 residents.

Airborne particulate matter has become a major air quality issue of public concern in recent years. The main sources of particulate matter are coal mining, surface soils (wind erosion), electricity generation, bushfires and prescribed burns [2]. In 2011 the NSW Environment Protection Authority (EPA, incorporating the Office of Environment and Heritage or $\mathrm{OEH}$ ) established the Upper Hunter Air Quality Monitoring Network. This network consists of 14 monitoring stations and provides the local community with information about particulate matter levels in the region. It also aids in identifying emission sources and helps to inform regulatory programs to reduce emissions [3].

Emissions to air due to mining are from a variety of activities including material handling, material transport, processing, wind erosion, blasting and potentially spontaneous combustion of coal. These emissions mainly comprise of particulate matter (as TSP, $\mathrm{PM}_{10}$ and $\mathrm{PM}_{2.5}$ ). 


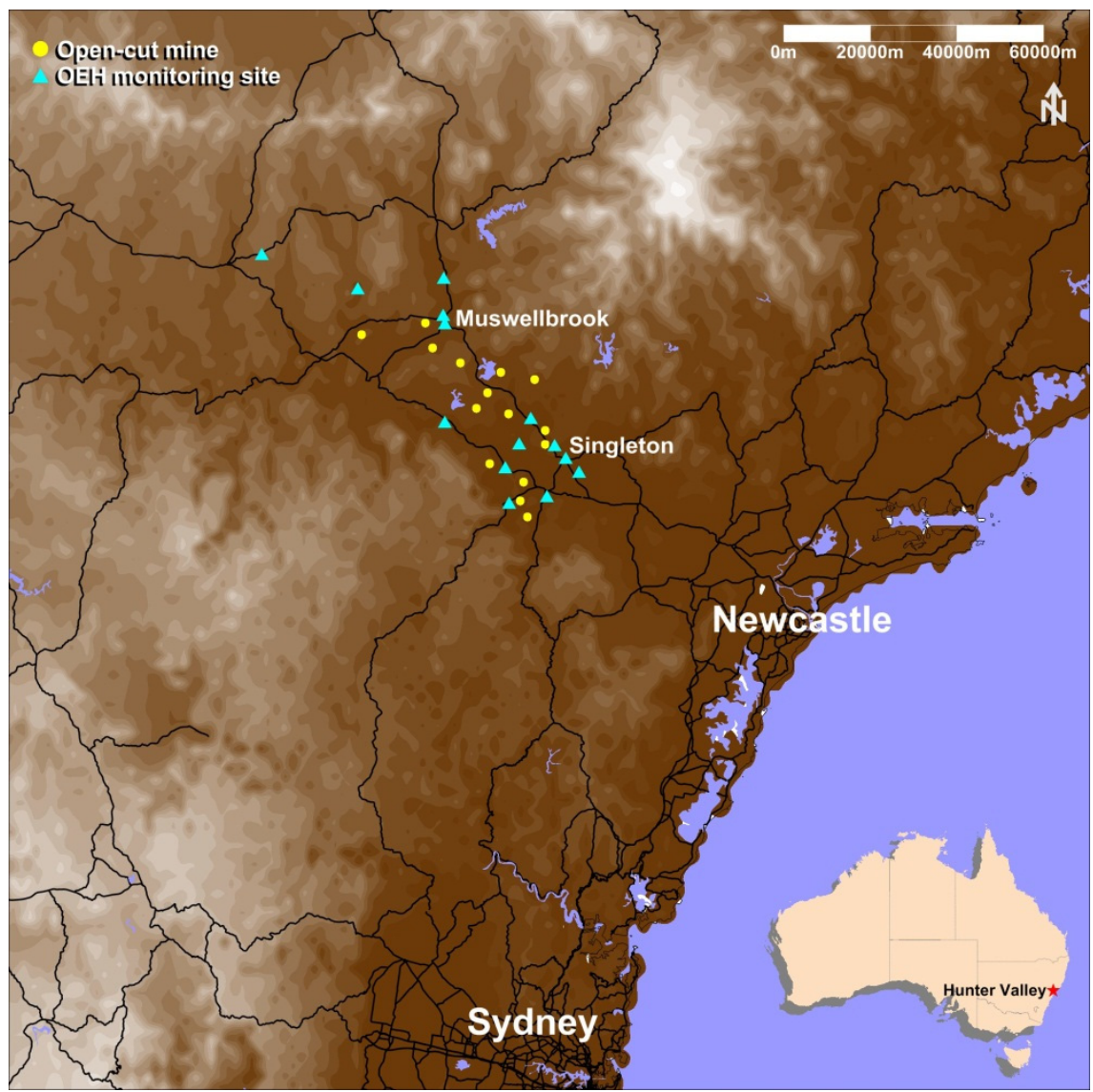

Figure 1: The Hunter Valley, mining operations and air monitoring sites.

An important aspect of protecting local air quality is to minimise the dust generated from the coal mining activities. Operations are required by environment protection licences and project approval conditions to meet certain criteria for ambient air quality. In order to meet these criteria, coal mines must manage the dust emissions from their activities in a competent manner. Assisting with the management of emissions is one of the objectives of the forecasting system, described below.

\section{Forecasting system objectives}

To assist with the management of dust emissions from coal mines in the Hunter Valley, the Australian Coal Association Research Program (ACARP) funded a project (C19034) to develop an emission estimation and air dispersion modelling system. The initial objective of the system was to issue dust and meteorological forecasts so that site operators can assess whether to implement suitable emission 
reduction measures in advance of adverse weather or dust risk. Another objective of the system was to simply raise awareness of environmental issues across Hunter Valley mine sites.

The forecasting system consists of a computer-based air dispersion model that uses estimates of dust emissions and forecasts of meteorology to predict ambient dust concentrations in the Hunter Valley, for up to two days in advance. The key output of the system is a dedicated web-site that can be accessed at any time by relevant stakeholders, and/or mine site operators. A daily forecast email is also produced. The forecasts are intended to facilitate appropriate mine planning in order to manage potential environmental impacts.

It was determined that the success of the system would depend on a number of factors including:

- $\quad$ Time impost. The desire was for environmental information to be conveyed to end-users with minimal time impost, for use in site communication material at the start of each shift or daily planning meeting.

- Interpretation. Ease of interpretation was important for identifying appropriate responses to environmental risks.

- Performance. Demonstrated performance was a key factor for gaining acceptance by end-users.

The final system consisted of:

- An environmental forecast summary report emailed to various site personnel and stakeholders each morning.

- A website that allows end users to gain a better understanding of the detailed information used to support the environmental forecast report.

This form of system was chosen to address the success factors identified above. The system also indirectly addressed conditions of approval relating to the implementation of air quality management systems.

Initial system development commenced in 2010 and was followed by consultation at various sites, with feedback collected on usage and potential improvements.

\section{System configuration}

\subsection{Model selection}

The model selection considered the expected transport distances for the emissions, as well as the potential for temporally and/or spatially varying flow fields due to influences of complex terrain, non-uniform land use, coastal effects, and stagnation conditions characterised by calm or very low wind speeds with variable wind directions. These complexities are relevant to the area of interest.

The non-steady-state model known as TAPM ("The Air Pollution Model") was selected for this project, based on a consideration of the project objectives, the 
scale of the prediction domain, and the potential cumulative effects of many emission sources. TAPM is a prognostic model, developed by CSIRO, which predicts three-dimensional meteorology and air pollution. TAPM is further discussed in the model's user manual [4] and various model verification studies (see for example [5]). Model settings for TAPM are shown in Table 2.

Table 2: $\quad$ Key model settings for TAPM.

\begin{tabular}{|l|l|}
\hline Parameter & Value \\
\hline TAPM version & 4.0 .5 \\
\hline Centre of analysis & $32^{\circ} 28^{\prime} \mathrm{S}, 150^{\circ} 55.5^{\prime}$ E \\
\hline Number of model domains & 3 \\
\hline Model domain 1 & $1000 \mathrm{~km} \times 1000 \mathrm{~km}$ with $10 \mathrm{~km}$ spacing \\
\hline Model domain 2 & $300 \mathrm{~km} \times 300 \mathrm{~km}$ with $3 \mathrm{~km}$ spacing \\
\hline Model domain 3 & $100 \mathrm{~km} \times 100 \mathrm{~km}$ with $1 \mathrm{~km}$ spacing \\
\hline Number of grid points & $100 \times 100 \times 25$ \\
\hline Synoptic data & CCAM \\
\hline Terrain data & AUSLIG \\
\hline Soil, vegetation, LAI & USGS \\
\hline Simulation period & One “spin-up" day, plus two simulation days \\
\hline $\begin{array}{l}\text { Meteorological data } \\
\text { assimilation }\end{array}$ & None \\
\hline Pollution model & Dust, with deposition and settling \\
\hline Pollutant grid dimensions & $90 \times 90$ \\
\hline $\begin{array}{l}\text { Background PM } \\
\text { concentration }\end{array}$ & $\begin{array}{l}5 \mu \mathrm{gg} / \mathrm{m}^{3}, \text { to account for non-modelled } \\
\text { emission sources }\end{array}$ \\
\hline
\end{tabular}

\subsection{Emissions}

Dust emissions arise from various activities in the Hunter Valley, including anthropogenic and natural sources. Total annual dust emissions due to the active mining operations were determined from a review of relevant air quality assessments prepared as part of project applications and approval documentation. The air quality assessments provided dust emission estimates based on material handling schedules, equipment inventories and mine plans for selected years of operation.

In general, the air quality assessments combined the anticipated operations with emissions factors drawn largely from the following sources:

- Emission Estimation Technique Manual for Mining [6]

- $\quad$ AP $42[7]$ 
Table 3 provides the annual dust emission estimates for 2011 from mining operations (refer to Figure 1), derived from the literature review [8]. Dust emissions that were not available directly for each year were interpolated from available estimates, or extrapolated to the development consent year for that operation. It is important to note that the emissions used in the modelling system do not cover all particulate matter emission sources in the Hunter Valley; the system has a focus on the contribution from active mining operations and natural wind erosion sources only.

Table 3: Estimated annual dust emissions for 2011.

\begin{tabular}{|c|c|}
\hline Mine & Year 2011 TSP emissions $(\mathrm{kg} / \mathrm{y})$ \\
\hline Ashton & - \\
\hline Bengalla & $7,736,842$ \\
\hline Bulga & $5,380,417$ \\
\hline Carrington & 996,522 \\
\hline Cumnock & $2,406,642$ \\
\hline Drayton & $6,327,802$ \\
\hline Glendell & - \\
\hline HVO South & $10,742,494$ \\
\hline Integra & $2,901,188$ \\
\hline Liddell & $6,919,279$ \\
\hline Mangoola & $1,819,535$ \\
\hline Mt Arthur Coal & $18,591,695$ \\
\hline Mt Owen & $4,762,555$ \\
\hline Mt Thorley & $8,737,591$ \\
\hline Muswellbrook Coal & 972,967 \\
\hline Ravensworth & $1,248,000$ \\
\hline Ravensworth East & $5,254,091$ \\
\hline Rixs Creek & $3,274,517$ \\
\hline United & - \\
\hline Wambo & $5,126,889$ \\
\hline Warkworth & $8,276,315$ \\
\hline West Pit & $4,207,897$ \\
\hline
\end{tabular}

Mining operations were represented by a series of volume sources located according to the centre of key dust generating activities. Figure 2 shows the 
location of modelled sources that were used to represent active mining operations. The emissions from the mining operations listed in Table 3 were assigned to one or more of these source locations.

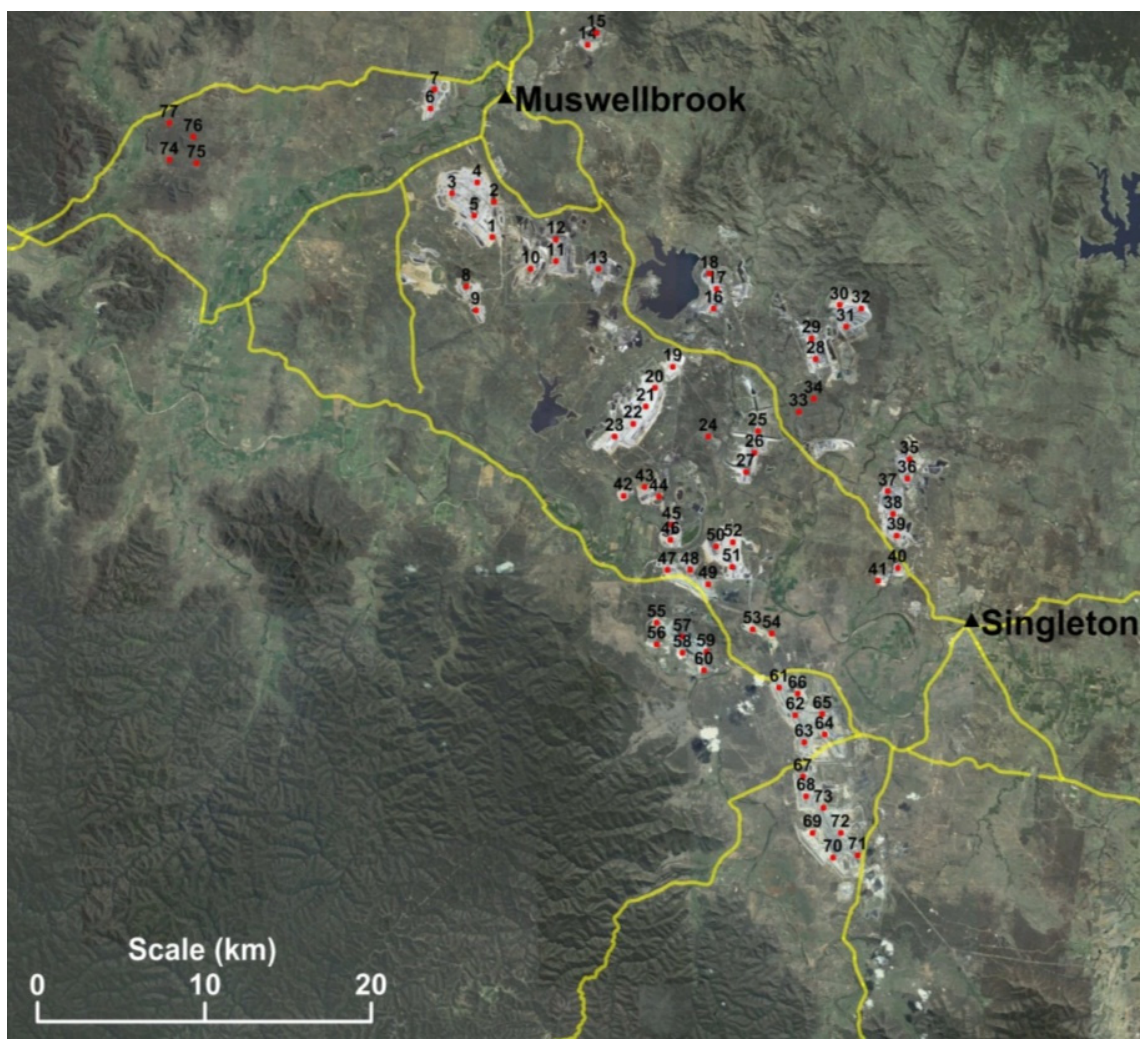

Figure 2: Location of modelled mining dust sources.

Dust emissions for all modelled mining operations have been considered to fit into one of three categories, as follows:

- Wind insensitive sources, where emissions do not vary with wind speed (for example, trucks transporting overburden over unsealed roads);

- Wind sensitive sources, where emissions vary with the hourly wind speed, raised to the power of 1.3 (for example, trucks loading and unloading); and

- Wind erosion sources, where emissions vary with the wind speed, raised to the power of 3 (for example, wind erosion from stockpiles).

The proportion of emissions in each category has been estimated from the TSP emission estimates by using the following fractions: 
- $\quad 0.48$ for emissions independent of wind speed;

- 0.18 for emissions that depend on wind speed; and

- $\quad 0.34$ for wind erosion sources.

The fractions above were derived from an analysis of the distribution of emission estimates in each category from air quality assessments carried out for Bengalla, Carrington, Warkworth, Mt Arthur and Mangoola mines. Finally, $\mathrm{PM}_{10}$ emissions were estimated from the TSP emissions by assuming that $\mathrm{PM}_{10}$ is $39 \%$ of the TSP emission [9].

\subsection{Meteorology}

Synoptic analyses are provided by the Cubic-Conformal Atmospheric Model (CCAM), developed by CSIRO (see the user manual for more information [10]).

\section{System outputs}

The outputs of the system are a daily forecast email and a dedicated web-site that can be accessed at any time by relevant stakeholders, and/or mine site operators. Forecasts are available by approximately 7 am each morning. The URL for the system is http://hunter.envforecasting.com.

Figure 3 shows an example of the main page of the website.

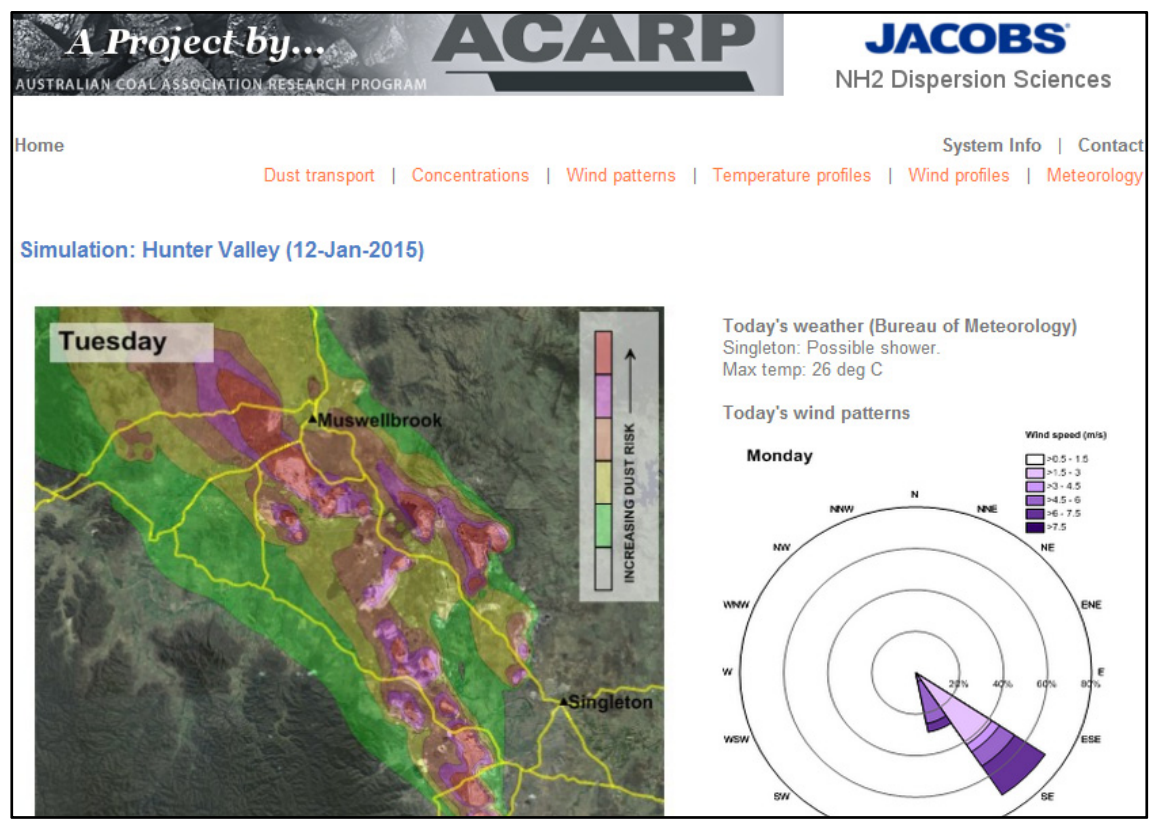

Figure 3: Screenshot of the website main page. 
Table 4 lists the content and interpretation of selected pages on the web-site.

Table 4: Website pages and interpretation.

\begin{tabular}{|c|c|}
\hline Page & Description \\
\hline $\begin{array}{l}\text { Home page: } \\
\text { - Daily dust risk } \\
\text { forecasts, cycling } \\
\text { between "today" and } \\
\text { "tomorrow" } \\
\text { - A descriptive weather } \\
\text { forecast from the } \\
\text { Bureau of } \\
\text { Meteorology } \\
\text { - "Today's" wind } \\
\text { patterns }\end{array}$ & $\begin{array}{l}\text { The contours on the plot represent the predicted 24-hour average } \mathrm{PM}_{10} \\
\text { concentrations, as a dust risk index, due to the modelled emission sources. The } \\
\text { concentration bounds are consistent with the "Air Quality Index" used by the Office } \\
\text { of Environment and Heritage. For the definition, see } \\
\text { http://www.environment.nsw.gov.au/aqms/definitions.htm. } \\
\text { The windrose shows the predicted pattern of winds for the day (as frequency of } \\
\text { speeds and directions). } \\
\text { Objectives } \\
\text { The main objectives of this page are to: } \\
\text { - } \quad \text { Highlight areas of potentially increased dust risk } \\
\text { - Compare today's forecasts with tomorrow's forecasts } \\
\text { - Provide a snapshot of today's wind patterns } \\
\text { Interpretation } \\
\text { - Forecasts in the index bands towards RED suggest that there is increased } \\
\text { dust risk } \\
\text { The comparison between today and tomorrow, and wind patterns, are } \\
\text { intended to inform decisions on mine planning } \\
\text { Weather description should be examined to assess whether forecasts are } \\
\text { appropriate. For example, less emphasis should be placed on the dust } \\
\text { forecasts when rain is expected or occurring }\end{array}$ \\
\hline $\begin{array}{l}\text { Dust transport page: } \\
\text { - Forecasts of dust } \\
\text { transport by hour of } \\
\text { day, for "today" and } \\
\text { "tomorrow" } \\
\text { - Wind vectors by hour } \\
\text { of day, for "today" } \\
\text { and "tomorrow" }\end{array}$ & $\begin{array}{l}\text { The contours on the plot represent the predicted 1-hour average } \mathrm{PM}_{10} \text { concentrations, } \\
\text { as an hourly dust risk, where the concentration bounds are double those of the daily } \\
\text { (24-hour average) dust risk index. Wind-vectors show the predicted variation in wind } \\
\text { speed and wind direction across the region, for each hour. } \\
\text { Objectives } \\
\text { The main objectives of this page are to: } \\
\text { - } \quad \text { Highlight when and where there is increased dust risk } \\
\text { - Compare today's forecasts with tomorrow's forecasts } \\
\text { Interpretation } \\
\text { - Forecasts towards the RED category suggest that there is increased dust risk } \\
\text { - The hourly transport forecasts and comparison between today and tomorrow, } \\
\text { are intended to inform decisions on mine planning }\end{array}$ \\
\hline $\begin{array}{l}\text { Concentrations page: } \\
\text { - Hourly forecasts of } \\
\mathrm{PM}_{10} \text { concentrations }\end{array}$ & $\begin{array}{l}\text { The graphs show the predicted 1-hour average } \mathrm{PM}_{10} \text { concentrations, as an hourly dust } \\
\text { risk, at Singleton and Muswellbrook, the two main towns in the Hunter Valley. } \\
\text { Objectives } \\
\text { The main objective of this page is to: } \\
\text { - } \quad \text { Highlight times of predicted increased dust risk } \\
\text { Interpretation } \\
\text { - Increased dust risk should be assessed in terms of general times of the day. } \\
\text { - For example, morning or afternoon, rather precise times such as 7:30 am } \\
\text { The forecasts are intended to inform decisions on mine planning }\end{array}$ \\
\hline $\begin{array}{l}\text { Wind patterns page: } \\
\text { - Windroses (today and } \\
\text { tomorrow) }\end{array}$ & $\begin{array}{l}\text { The windroses are developed from forecasts of wind speed and wind direction data at } \\
\text { the centre of the Hunter Valley. These are not specific to any one mine site but } \\
\text { represent the general pattern of winds expected for the region. } \\
\text { Objectives } \\
\text { The main objectives of this page are to: } \\
\text { - Provide a comparison between wind patterns for "today" and "tomorrow" } \\
\text { Interpretation } \\
\text { - Wind patterns should be assessed in terms of being favourable or } \\
\text { - unfavourable for dust generating activities, and nearest sensitive receptors } \\
\text { The forecasts are intended to inform decisions on mine planning }\end{array}$ \\
\hline
\end{tabular}

\section{Results}

Over a period of 24 months, interest in receiving daily forecasts increased from initially 1 or 2 two sites to around 10 sites, as well as regulators and service 
providers. The diversity of recipients has also increased with interest from not only environmental officers, but also production supervisors, dispatchers, operational supervisors and functional managers. This allows for more informed decisionmaking to occur with a better understanding of potential impacts based on the current level of mining activity at each site. The forecasts are typically tabled and discussed at daily pre-shift meetings. These results have indicated an increased awareness of environmental issues at various levels.

An important factor in raising employee awareness of environmental issues was to demonstrate the typical performance of the system to end-users. Over a 12month period, model predictions of meteorological conditions were compared to observations, focusing on wind speed and direction, among other variables. The main aim of these evaluations was to identify when the system performed well or poorly and to establish a level of confidence in the predictions.

Figure 4 shows the measured and predicted hourly winds over a one week period. These results are indicative of the meteorological prediction performance that was observed over the 12-month evaluation period.
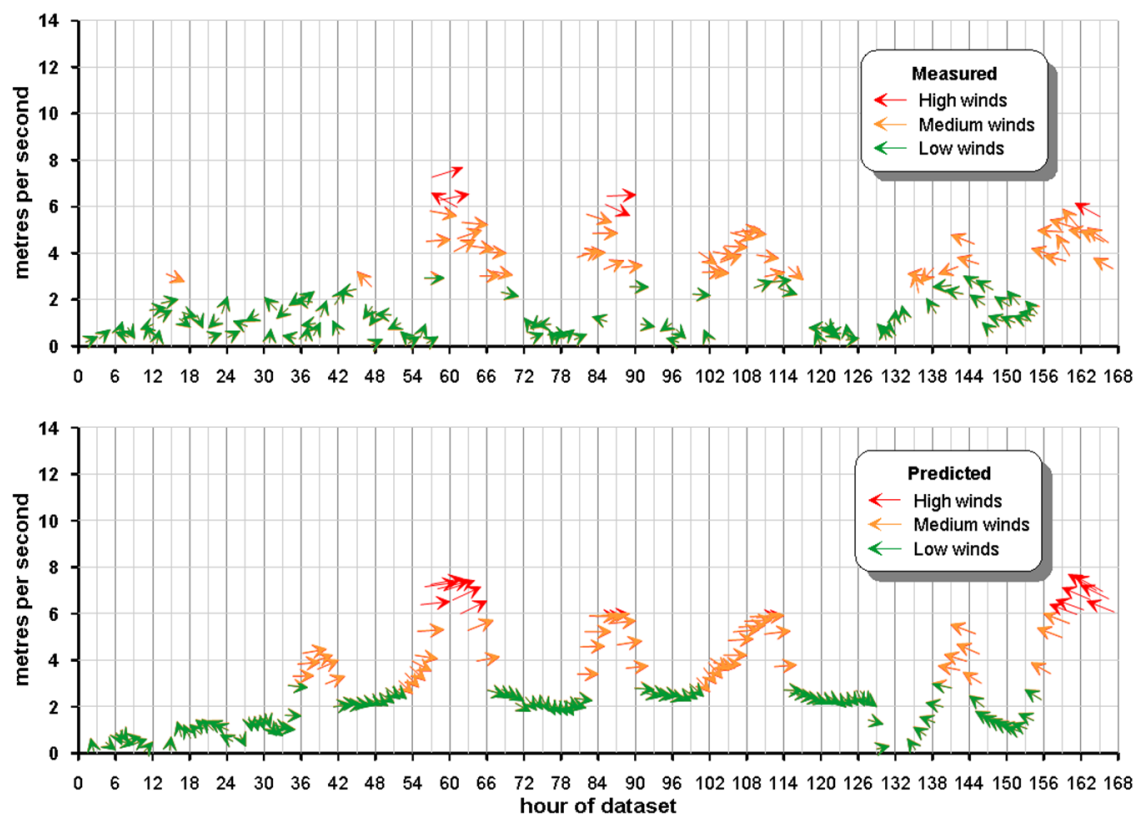

Figure 4: Measured and predicted hourly winds over a one week period.

From Figure 4 it can be seen that the general trends in wind speed and direction are predicted well, but some of the fine scale variations are not always resolved.

The performance of the system was also evaluated by comparing predicted and measured 24-hour average $\mathrm{PM}_{10}$ concentrations at Muswellbrook and Singleton for a one month period. The system was placed in forecast mode for a one month period, between March and April 2011. Concurrent measurement data collected 
by the Office of Environment and Heritage at their Muswellbrook and Singleton air quality monitoring sites were obtained. Rain days were excluded from the evaluation.

Table 5 provides a summary of the differences between measured and predicted dust risk index for Muswellbrook and Singleton, over the evaluation period. Based on these results, the system predicted the dust risk index within one index band for approximately $80 \%$ of the time, at both Singleton and Muswellbrook. The system does not simulate the dispersion of all dust emission sources in the Hunter Valley (for example, motor vehicles, domestic heating, or agricultural activities etc.) so the comparison between measurement data and predicted data could not be expected to yield close agreement under all or even most circumstances. However, in terms of the contribution from active mining operations, the system appears to be useful for highlighting increased relative dust risk.

Table 5: Summary of differences between measured and predicted dust index.

\begin{tabular}{|l|c|c|}
\hline & Muswellbrook & Singleton \\
\hline $\begin{array}{l}\text { Total non-rain-days in model performance evaluation } \\
\text { period }\end{array}$ & 18 & 18 \\
\hline $\begin{array}{l}\text { Number of days when difference was less than or } \\
\text { equal to 1 index band }\end{array}$ & 15 & 15 \\
\hline $\begin{array}{l}\text { Number of days when difference was greater than 1 } \\
\text { index band }\end{array}$ & 3 & 3 \\
\hline
\end{tabular}

\section{Conclusions}

The mining industry in the Hunter Valley is generally pro-active in relation to managing dust emissions. This is demonstrated by the development of site specific and regional systems to predict daily dust risks, such as the system developed as part of ACARP Project C19034 and discussed in this paper. This system has led to an increased awareness of environmental issues across many mine sites. Feedback from end users has suggested that the simplistic nature of the output is the main factor for the increased interest in the system, as the potential dust risks can be quickly and easily identified.

The focus of the system is primarily on the active mining sources and inclusion of additional emission sources, such as emissions from population centres, may produce a more realistic picture of overall air quality in the Hunter Valley. Further work could involve improving the emission estimation, especially during rainfall events, to improve the overall performance of the system.

\section{Acknowledgements}

The author would like to thank Nigel Holmes of NH2 Dispersion Sciences and ACARP for making this work possible. Also thanks to those personnel at sites in the Hunter who have provided ongoing feedback on the system. 


\section{References}

[1] Development Consent, SSD-4960, Bulga Optimisation Project. Available from http://majorprojects.planning.nsw.gov.au/.

[2] Environment Protection Authority (2013) "Upper Hunter Air Particles Action Plan". http://www.epa.nsw.gov.au/resources/aqms/20130158 uphunterapap.pdf.

[3] Office of Environment and Heritage http://www.environment.nsw.gov.au/aqms/uhunteraqmap.htm.

[4] Hurley, P. (2008). TAPM v.4. User manual. CSIRO Marine and Atmospheric Research, PMB 1, Aspendale 3195, Australia.

[5] Hurley, P., Edwards, M., Luhar, A., \& Thatcher, M. (2009). "Evaluating the meteorological performance of TAPM". Proceedings of the 19th International Clean Air and Environment Conference.

[6] NPI (2001). "Emissions estimation technique manual for mining - version 2.3". Environment Australia, GPO Box 787, Canberra, ACT 2601.

[7] US EPA (1985 and updates). "Compilation of air pollutant emission factors". United States Environmental Protection Agency, Office of Air and Radiation Office of Air Quality Planning and Standards.

[8] ACARP (2011) "Use of Meteorological Models to Predict Dust Risk Indices for Mining Areas in the Hunter Valley”. ACARP Project C19034.

[9] SPCC (1986) "Particle size distributions in dust from open cut coal mines in the Hunter Valley". Report no. 10636-002-71. Prepared for the State Pollution Control Commission (now EPA) by Dames \& Moore.

[10] Thatcher, M (2007). CCAM GUI instruction manual for TAPM users (v709t). PMB 1, Aspendale 3195, Australia: CSIRO Marine and Atmospheric Research. 